\title{
A FACE OPACA DA REPÚBLICA: IZABEL ESTEVES DE FREITAS E AS ESCOLAS DE PRIMEIRAS LETRAS EM ITABAIANA (1926-1932)
}

\author{
Magno Francisco de Jesus Santos ${ }^{1}$
}

\begin{abstract}
RESUMO
Neste artigo temos o intuito de compreender as nuances da professora Izabel Esteves de Freitas durante a Primeira República na escola de primeiras letras. Este foi um período em que a cidade de Itabaiana passou importantes transformações. A cidade que há pouco tempo deixara de ser vila transformava-se rapidamente. A reflexão seguiu os insumos teóricos e categorias analíticas de Pierre Bourdieu, através das quais pudemos observar os principais aspectos da realidade educacional sergipana durante a Primeira República, com ênfase para a vida educacional de Itabaiana, apresentada por meio da escola que estava sob a responsabilidade da professora Izabel Esteves de Freitas. Com isso, tornou-se possível compreender a educação nas primeiras décadas republicanas por um ângulo diferenciado, oposto à visão tradicional preza aos grupos escolares.

Palavras-chave: História da Educação, escola isolada, Primeira República, avaliação, docência.

\section{THE OPAQUE FACE OF THE REPUBLIC: IZABEL ESTEVES DE FREITAS AND FIRST LETTERS SCHOOLS IN ITABAIANA (1926-1932)}

\begin{abstract}
In this article we have in order to understand the of teacher Izabel Esteves de Freitas during the First Republic in the few first letters school. This was a period when the city passed Itabaiana City important transformations. The city that recently ceased to be village turned up quickly. The reflection followed the theoretical inputs and analytical categories of Pierre Bourdieu, through which we could observe the main aspects of the educational reality of Sergipe during the First Republic, with emphasis on the educational life of Itabaiana, presented by the school which was under the responsibility of professor Izabel Esteves de Freitas. With this, it became possible to understand education in the early decades of the Republic by a different angle, as opposed to the traditional view holds dear to school groups.
\end{abstract}

Keywords: History of Education, school isolated, First Republic, assessment, teaching.

\section{Introdução}

Um visitante, ao andar pelas ruas calamitosas do centro comercial de Itabaiana depara-se com um mundo a parte. Se tiver um olhar aguçado, este visitante pode passar demoradamente pela feira, observando seus excêntricos personagens, que quase tudo negocia. Ao passar pela tumultuada feira das panelas, o curioso viajante pode ficar diante de uma pequena escola, denominada Professora Izabel Esteves de Freitas. Pequena e acanhada, a estrutura arquitetônica da edificação não prende a atenção do observador. No entanto, uma inquietação paira sobre o pesquisador. Quem teria sido a professora que emprestou o seu nome a essa escola da cidade de Itabaiana? Talvez o problema não seja saber quem teria sido a mestra, mas sim desvendar o que ela teria feito para que hoje o seu nome fosse atribuído a uma construção pública da cidade.

Para muitos, Izabel Esteves de Freitas não passa de uma anônima, ou no máximo, uma denominação escolar com pouca significação. No universo intelectualizado, a referida 
professora foi descoberta há pouco tempo, com os estudos sobre algumas personalidades que foram seus alunos ou de instituições nas quais atuou. Deste modo, a professora foi citada em notas breves, em estudos como a biografia de Maria Thetis Nunes (sua ex-aluna) de Maria Nely Santos e na história de Itabaiana publicada por Vladimir Souza Carvalho. Foi a partir destas notas esparsas que a professora emerge enquanto objeto da historiografia educacional sergipana.

O interesse em estudar a escola da professora Izabel Esteves de Freitas surgiu com a descoberta de um documento no Arquivo Público Estadual de Sergipe. Trata-se do termo de exames finais da referida escola durante a Primeira República. É instigante estudar uma escola isolada neste período, pois foi a época na qual foi disseminado por todo o país os benefícios propiciados pelo ensino dos grupos escolares, proclamados como um dos principais símbolos do regime republicano no campo educacional.

Estudar esta modalidade de ensino representa rever a força do discurso republicano, a permanência do modelo adotado no período imperial, ou seja, analisar a educação do novo regime por um ângulo diferenciado. O discurso oficial da República elaborou fortes críticas ao modelo de ensino realizado nas escolas isoladas tais críticas podem ser constatadas nos diversos relatórios e mensagens dos presidentes do Estado de Sergipe nas primeiras décadas do século XX.

Partindo da relevância desta temática para os estudos da historiografia educacional referente ao período republicano, temos o intuito de compreender as nuances da trajetória da escola número um de Itabaiana, que estava a cargo da professora Izabel Esteves de Freitas durante a Primeira República. Este foi um período em que a cidade de Itabaiana passou importantes transformações nos setores políticos, econômicos, sociais, intelectuais e educacionais. A cidade que há pouco tempo deixara de ser vila transformava-se rapidamente.

A reflexão seguiu alguns dos aportes teóricos estabelecidos nas obras de Pierre Bourdieu, principalmente no que concerne aos conceitos de campo, capital simbólico e habitus. O campo pode ser definido como o espaço de lutas no qual seus agentes disputam um melhor posicionamento no interior do mesmo (CHAMPAGNE, 2004), ou seja, "o universo no qual estão inseridos os agentes e as instituições que produzem, reproduzem ou difundem a arte, a literatura ou a ciência" (BOURDIEU, 2004, p. 20). Neste ensejo, podemos dizer que em um campo o posicionamento de seus agentes não é estratificado, por está em constante processo de redefinição. Nas disputas pela melhor posição no interior do campo está atrelado ao acúmulo de capital simbólico. Para que isso ocorra torna-se necessário o Habitus, visto como "maneiras de ser permanentes, duráveis que podem, em particular, levá-los a resistir, a opor-se às forças do campo" (BOURDIEU, 2004 , p. 28). O campo é "o objeto de luta tanto em sua representação quanto a sua realidade" (BOURDIEU, 2004, p. 29).

Habitus é conceituado pelo autor como o "princípio gerador de estratégias inconscientes ou parcialmente controladas tendentes a assegurar o ajustamento às estruturas de que é produto tal princípio" (BOURDIEU, 2005, p.160). Assim, ao inseri-se no campo o agente passa a acumular uma série de disposições necessárias a sua permanência no campo, de modo mais simples, seriam as regras do jogo.

A reflexão está dividida em três momentos. No primeiro discutimos o confronto através dos discursos das autoridades educacionais entre os modelos de ensino dos grupos escolares e das escolas isoladas, no plano nacional, estadual e municipal. No segundo apresentamos uma breve trajetória da vida educacional de Itabaiana, enfatizando a criação das escolas isoladas. Por fim, discutimos a escola número um de Itabaiana no período em que esteve sob a coordenação da professora Izabel Esteves de Freitas. 


\section{A educação em tempos de República}

Durante todo o período imperial o modelo educacional primário predominante no Brasil foi o das escolas isoladas ou de primeiras letras. Tradicionalmente, este modelo é apresentado pela historiografia educacional como sendo um representante do atraso educacional. É provável que essa conclusão seja originária dos discursos republicanos nas primeiras décadas do século XX, que buscou confrontar o suposto atraso do ensino das escolas isoladas com os avanços propiciados pelos grupos escolares. Mais do que uma discussão a respeito do modelo de escola mais adequado, as discussões nas primeiras décadas do século XX refletem a busca dos republicanos em legitimar o regime político recém-implantado. Ao condenar o ensino das escolas isoladas, apresentado como desorganizado e precário, criticava o regime monárquico, levando-se em consideração que esta foi a forma preponderante no referido período.

A tese defendida pelos republicanos e adotada pela historiografia educacional deve ser revista. É oportuno rever a relevância das inúmeras escolas isoladas que foram difundidas por todo o país, tanto na Monarquia como na República. Se os grupos escolares eram apresentados como o modelo ideal para o Brasil Republicano, eram as escolas isoladas que fortaleciam a democracia, um dos principais pressupostos do novo regime, ao passo que a maior parte do alunado estava neste tipo de escola.

Durante todo o período colonial a educação brasileira estava a cargo majoritariamente, dos jesuítas. Com expulsão dos inacianos a educação fica à mercê, pois não havia a princípio como substituí-lo. Entre 1759 e 1808 houve "hiatos de desorganização e decadência do ensino colonial" (AZEVEDO, 1980, p. 61). Foi somente com a chegada da família real que o ensino primário voltou a se estruturar gradualmente, com a implantação das cadeiras de primeiras letras.

Estas cadeiras foram difundidas por todo o país. $\mathrm{O}$ ensino nas escolas isoladas era multi-seriado, na qual uma professora ficava responsável pelo ensino de alunos de séries distintas. Além disso, as escolas funcionavam em instalações improvisadas, como casas das professoras, salões paroquiais ou casas alugadas pelo poder público. Tais aspectos fizeram com que este modelo de ensino fosse visto como decadente, precário e desorganizado.

Com a implantação do regime republicano as críticas referentes às escolas isoladas tornaram-se assíduas. Os intelectuais da educação, através de relatórios e mensagens, passaram a confrontar sistematicamente os dois modelos de ensino primário em vigor: escola isolada e grupo escolar. Este foi adotado pelos republicanos como escola-símbolo do novo regime. Com a emergência do entusiasmo pela educação, a escola passou a ser vista como uma das principais soluções dos problemas que afligiam a sociedade brasileira. E educação era o mecanismo para fortalecer a democracia, levando-se em consideração que nas eleições da República Velha só votavam os brasileiros considerados alfabetizados. Neste sentido, ensinar era sinônimo de inclusão da sociedade no regime recém-implantado, representava a legitimação da democracia republicana, contrapondo-se à monarquia.

Mesmo o ensino primário tendo sido eleito pelos republicanos como prioridade, as deficiências do ensino tiveram dificuldades em serem sanadas. Os constantes problemas financeiros que atingiam os cofres públicos emperraram os avanços sonhados para o ensino primário. Assim como no Império, a educação continuava a ser um dos grandes problemas enfrentados pela nação brasileira na República. Esta constatação está explícita em mensagens de presidentes dos estados, como o do general Oliveira Valadão em 1916, alegando ser "como um dos graves problemas nacionais, cuja solução deve ser promovida 
sem vacilações, tem sido o ensino público objecto de especial solicitude da minha administração" (VALADÃO, 1916, p. 19).

Apesar das constantes inovações no campo educacional, com a chegada de novas metodologias de ensino, a prática docente permanecia deficitária com a faltas dos recursos didáticos e funcionando em instalações inapropriadas. A precariedade das instituições escolares foi apresentada como o maior empecilho à difusão das novas propostas pedagógicas, pois "a notória pobreza das nossas escolas foi sempre obstáculo que annullava as melhores energias dos dirigentes de ensino" (VALADÃO, 1916, p. 19). Neste ponto, podemos perceber uma contradição entre o discurso oficial que enaltecia os supostos avanços contínuos do setor educacional e a realidade vivenciada na maioria das escolas, que eram marcadas pelos parcos recursos e precariedade das instalações.

A preocupação no tocante ao setor educacional era em relação ao ensino primário. Como vimos esta preocupação não era desproposital, por camuflar os anseios de legitimação do regime. A relevância do ensino primário era assim justificada pelas autoridades:

Com particular carinho, olho para o ensino primário que, no sentenciar de um illustre pedagogo, é o recomeço de todo o saber. "Por elle- diz o grande sábio-tiveram de passar os espíritos mais cultos, os sábios mais iminentes, antes de penetrar no santuário da Sciencia". Muito embora elle pese consideravelmente no orçamento da despesa publica, não devemos medir sacrifícios quando tratados de dissipar as trevas da ignorância e ampliar o horizonte intellectual de nossos patrícios (LOBO, 1921, p. 13).

Enquanto que no estado de São Paulo os grupos escolares começaram a ser implantados ainda na década de 1890, em Sergipe o mesmo ocorreu de forma relativamente tardia, duas décadas após. É importante salientarmos que a implantação dos grupos escolares não significou o desmonte da estrutura das escolas isoladas, pelo contrário, estas escolas continuaram sendo criadas na maioria das cidades, vilas, povoados e até na capital do Estado. Os faustosos grupos localizados geralmente nos entornos do centro contrastavam com as centenas de escolas isoladas espalhadas por toda a cidade.

É impressionante o número de alunos matriculados nas escolas isoladas durante as primeiras décadas do século XX. Mesmo os discursos oficiais enaltecendo a relevância dos grupos escolares, a maioria do alunado estava matriculada nas tidas defasadas escolas isoladas. Este dado pode ser evidenciado na tabela a seguir, que demonstra a distribuição de instituições escolares de Sergipe em 1922:

QUADRO I

Distribuição das Instituições Escolares de Sergipe em 1922

\begin{tabular}{|c|c|}
\hline Instituição Escolar & Número de Estabelecimentos \\
\hline $\begin{array}{c}\text { Atheneu Sergipense, equiparado ao Dom Pedro } \\
\text { I }\end{array}$ & 01 \\
\hline Escola Normal & 01 \\
\hline Escola Complementar & 01 \\
\hline Grupos Escolares & 05 \\
\hline Escolas Isoladas na Capital & 15 \\
\hline Escolas Isoladas nas Cidades & 58 \\
\hline Escolas Isoladas nas Vilas & 43 \\
\hline Escolas Isoladas nos Povoados & 138 \\
\hline Escolas Noturnas & 07 \\
\hline
\end{tabular}

Fonte: Mensagem do Presidente do Estado de Sergipe de 1922, apresentada por Pereira Lobo. 
Os dados acima citados são reveladores, por expressarem a incongruência discursiva das autoridades educacionais republicanas. Ao todo eram 254 escolas isoladas, 07 escolas noturnas contra apenas 05 grupos escolares. Tais dados demonstram que, mesmo não consistindo o modelo de ensino almejado, as escolas isoladas desempenhavam a relevante função de difundir as primeiras letras entre a população sergipana. Deste modo, propagava-se o fortalecimento do regime democrático. O contraponto entre os dois modelos de ensino primário permaneceu por toda a primeira metade do século XX, criando divergências e polêmicas a esse respeito entre a intelectualidade sergipana (diretores de educação, governantes, professores, etc.).

Uma das propostas apresentadas pelas lideranças do setor educacional era de reunir as escolas isoladas formando grupos escolares mais modestos do que as imponentes construções das décadas de 1910 e 1920. As escolas seriam substituídas gradativamente pelos grupos. No entanto, esta proposta em termos reais não foi acatada, visto que as escolas isoladas continuavam sendo criadas nas mais variadas localidades. Apesar do suposto antagonismo entre os dois modelos educacionais, em termos práticos, escola isolada e grupo escolar se completavam na consolidação do regime em vigor.

A dualidade entre os modelos educacionais no setor primário revela aspectos que vão além das aparências. Trata-se da rivalidade, das intensas disputas entre as professoras por um melhor posicionamento no interior do campo educacional. Diferentes estratégias foram usadas pelo professorado visando assumir a vaga em um dos grupos escolares, vistos como o ápice da carreira docente feminina. Atuar em um dos poucos grupos edificados no Estado de Sergipe significava está em sintonia com os pressupostos estabelecidos pela pedagogia moderna, devido ao fato deles serem equipados com os mais modernos recursos pedagógicos de Sergipe na época. Nas escolas isoladas, apesar das professoras serem capacitadas para aplicarem os novos pressupostos metodológicos, a prática docente tornava-se prejudicada, devido à escassez do material pedagógico.

Outra questão que pode ser discutida a respeito da dualidade entre os grupos e as escolas isoladas refere-se aos custos dos cofres públicos. Devido ao seu caráter monumental, os grupos escolares demandavam um custo elevado para a arrecadação deficitária de Sergipe. Talvez esta seja uma das motivações que tenha propiciado a a continuidade na difusão das escolas isoladas. O número de escolas desta categoria que foram criadas em Sergipe no decorrer do século XX é surpreendente. Prova disso são as escolas criadas em 1936 no governo de Eronides de Carvalho, como pode ser observado no Quadro II, com dados da inspetoria da Instrução Pública:

Quadro II

Número de escolas isoladas criadas e providas em Sergipe no ano de 1936

\begin{tabular}{|c|c|}
\hline Classificação da localidade & Número de escolas \\
\hline Povoados & 29 \\
\hline Vilas & 05 \\
\hline Cidades & 05 \\
\hline Total & 39 \\
\hline
\end{tabular}

Fonte: Mensagem apresentada por Eronides de Carvalho em 1937.

Os dados da tabela II são reveladores da disposição do Estado de Sergipe em expandir a educação pública, doravante a permanência da necessidade da erradicação ou redução do analfabetismo. Isso explica a criação de 39 escolas em apenas um ano, ou seja, 
o ensino primário não se restringia apenas às cidades e vilas, mas sim a uma grande variedade de localidades distintas. Neste ensejo, mais uma vez constatamos que a ação republicana no campo educacional não deve ser vista de modo exclusivamente enquanto ruptura da tradição monárquica, mas pelo contrário, demonstrou algumas características de continuidade da política educacional vigente no Império Brasileiro. Trata-se de uma permanência com uma nova abordagem.

Os anseios educacionais não se limitavam à instalação de novas escolas. Um dos grandes impasses da educação sergipana na primeira metade do século XX consistia em reduzir a taxa de evasão escolar, que ainda permanecia elevada. Podemos suscitar uma série de questões que possam explicar o elevado número de alunos faltosos no ensino público sergipano, dos quais se destacam a distância entre a escola e a residência do aluno e a inserção das crianças no mercado de trabalho, seja este doméstico ou no cultivo. Apesar da criação de um maior número de estabelecimentos escolares por todo o Estado a evasão escolar continuava emperrando o desenvolvimento educacional sergipano. Observe os dados do Quadro III:

QUADRO III

O ensino primário sergipano no qüinqüênio 1933-1937

\begin{tabular}{|c|c|c|c|c|c|c|c|c|}
\hline Ano & \multicolumn{3}{|c|}{ ENSINO PÚBLICO } & \multicolumn{2}{c|}{ ENSINO MUNICIPAL } & \multicolumn{2}{c|}{$\begin{array}{c}\text { ENSINO } \\
\text { PARTICULAR }\end{array}$} \\
\cline { 2 - 9 } & $\begin{array}{c}\text { Unid. } \\
\text { escolar }\end{array}$ & Matrícula & Freqüência & $\begin{array}{c}\text { Unid. } \\
\text { escolar }\end{array}$ & Matrícula & Freq. & $\begin{array}{c}\text { Unid. } \\
\text { escolar }\end{array}$ & Matrícula \\
\hline 1933 & 366 & 13885 & 10726 & 46 & 1669 & 1310 & 68 & 2241 \\
\hline 1934 & 369 & 14600 & 11722 & 46 & 1671 & 1312 & 83 & 1952 \\
\hline 1935 & 387 & 19578 & 14558 & 70 & 2672 & 2265 & 68 & 2170 \\
\hline 1936 & 414 & 18149 & 14901 & 91 & 3315 & 2926 & 79 & 2615 \\
\hline 1937 & 456 & 18599 & 15397 & 143 & 5427 & 4578 & 82 & 3315 \\
\hline
\end{tabular}

Fonte: Mensagem apresentada por Eronides de Carvalho

Os dados constantes na tabela além demonstrarem o problema da evasão escolar, traz implicitamente a questão das disputas do interior do campo educacional. As mensagens e os relatórios dos presidentes de estado revelam uma disputa pelo alunado entre as escolas mantidas pelo estado e as mantidas pelos governos municipais. Era a corrida pela busca de uma mesma clientela.

Os impasses não ficavam restritos a discussão sobre o condicionamento das instalações das escolas. As disputam discursivas pairavam também entre os poderes públicos estadual, municipal e as escolas particulares em constante avanço no decorrer do século XX. No entanto, a maior deflagração ocorria entre as escolas do estado e dos municípios, pois estas disputavam o mesmo alunado.

\section{As aulas da mestra sergipana}

Uma educação tardia. O ensino formal demorou a ser implantado em terras itabaianenses. Somente no século XIX é que foram criadas as primeiras escolas, sem atingir sucesso de imediato. Em se tratar de educação em Itabaiana no dezenove devemos lembrar que foi um processo lento, gradual e marcado por avanços e retrocessos. $\mathrm{O}$ ensino primário em Itabaiana era sinônimo de precariedade e insegurança, pois as cadeiras eram criadas e extintas constantemente. Esta situação não era exclusividade da vila serrana durante o século XIX. Toda a província de Sergipe sofria com os percalços da educação pública. 
É provável que o ensino formal tenha chegado a terras itabaianenses poucos anos após a emancipação política de Sergipe, com a criação da cadeira de primeiras letras no ano de 1825 com o professor Joaquim Nunes. Pouco tempo depois foi criada uma cadeira de gramática latina, sob a regência dos professores Gonçalo Pinto Lobão e Joaquim Nunes no ano de 1829 (CARVALHO, 1973).

As duas cadeiras eram exclusivas para o alunado masculino. O sexo feminino só foi agraciado com uma escola a partir do ano de 1833, ano em que o decreto número 06 de 16 de fevereiro transfere a cadeira feminina da professora Carolina Julia de Vasconcelos da vila do Socorro para a vila de Itabaiana. Medidas como essa não eram tão raras na província de Sergipe. As escolas podiam ser transferidas de uma vila para outra sem dificuldades. O jogo político e as nuanças do campo educacional estavam juntos, pois o referido campo ainda estava aberto, configurando-se.

As duas escolas masculinas permaneceram em funcionamento até o ano de 1844, quando foi extinta a cadeira de gramática latina pela lei 127 de 18 de março que estava sob a regência do professor Antônio Dinis Barreto. A inconstância do ensino primário itabaianense aguçou-se em meados do século XIX, quando as cadeiras da vila eram criadas, extintas e transferidas constantemente. Prova desta situação de absoluta volubilidade é a extinção da cadeira feminina em 1850 (Resolução 299 de 04 de maio), apenas 17 anos após a transferência da vila do Socorro.

A vila serrana não passou muito tempo desprovida do ensino público. Em 1848 a resolução 221 de 22 de maio restaurou a cadeira de latim, novamente com o professor Antônio Dinis Barreto. Esta escola teria uma relevante importância para Itabaiana, tendo em vista que entre 1856 e 1859 a cadeira foi regida por Tobias Barreto de Meneses (aprovado em concurso público). Um ano após a chegada de Tobias Barreto, foi restaurada a cadeira de instrução primária do sexo feminino, com a resolução 460 de 20 de fevereiro. Coma saída de Tobias Barreto para realizar o curso de Direito na Faculdade do Recife, a escola de gramática latina ficou a cargo do padre Barbosa Guimarães. Deste modo, em 1865 Itabaiana possuía três escolas: a de gramática latina com dez alunos, uma primária do sexo masculino e outra do sexo feminino, regida pela professora Ceciliana Gomes de Oliveira.

Foi somente a partir da segunda metade do século XIX que as escolas isoladas foram disseminadas por toda a vila e seus povoados. Entre 1866 e 1884 foram criadas nove escolas de primeiras letras nos povoados de Itabaiana. Ainda neste período foi criada a escola elementar mista com a resolução 1221 de 25 de abril. Esta escola ficou a cargo da professora Epiphania Sergia da Silva.

O surgimento de um elevado número de escolas demonstra que a instrução pública já era uma preocupação durante o período imperial. A expansão do ensino primário começou ainda neste período, ou seja, os republicanos não inovaram ao propor a expansão do ensino primário. Esta constatação desmonta a tese do discurso republicano. Segundo os discursos republicanos ao longo do século XX, a educação só teria engrenado a partir da queda da monarquia. A educação imperial seria então indiferente, quase que sem efeito. Podemos supor que as preocupações acerca do universo educacional em Sergipe fortaleceram-se na segunda metade do século XIX. Neste sentido, a principal inovação prática dos republicanos ocorreu com a implantação dos grupos escolares.

A partir do século XX a educação itabaianense tomou novos rumos. A escola mista passou para a responsabilidade da professora Izabel Esteves de Freitas, que se tornaria uma das principais professoras do município. Varias personalidades itabaianenses foram alunas da professora Izabel Esteves de Freitas, entre elas a historiadora Maria Thetis Nunes, como atesta Maria Nely Santos: 
Desde criança, a escola - a grande e imensa paixão de sua vida-foi o local apropriado para revelar suas qualidades, aptidões e atributos. Aprendendo com rapidez e facilidade tudo que era ensinado, chamava à atenção das pessoas e em especial da professora Izabel Esteves de Freitas (SANTOS, 1999, p. 85).

A biografia escrita pela professora Maria Nely Santos demonstra a importância que Izabel Esteves de Freitas teve na sociedade itabaianense. Ela teria sido uma das responsáveis pela descoberta de Maria Thetis Nunes, umas das principais historiadoras de Sergipe. A professora Izabel lecionou na escola número um de Itabaiana entre as Décadas de 1920 e 1930, quando a escola foi extinta devido à criação do Grupo Escolar Guilhermino Bezerra. Os últimos anos de trabalho da professora em questão foram neste grupo, que se localizava na praça Santa Cruz, atual Praça João Pessoa.apesar de estarem sendo difundidos em Sergipe desde 1911, o grupo escolar somente foi implantado em Itabaiana no ano de 1937 com Silvio Teixeira e o interventor Eronides Ferreira de Carvalho, com o decreto número 05 de 27 de novembro. A finalidade do grupo foi a de reunir em suas salas amplas os alunos provenientes das diversas escolas isoladas espalhadas pela cidade. Com isso, foi o Grupo Escolar Guilhermino Bezerra "que reuniu em seu bojo os alunos dispersos em escolas isoladas de ponta de rua" (SANTOS, 1999, p. 127). Deste modo, a educação itabaianense tomava um novo rumo, adequando-se ao modelo proposto desde o final do século XIX no Estado de São Paulo, ou seja, o da pedagogia moderna.

Durante o período da regência da professora Izabel Esteves de Freitas na escola número um de Itabaiana, um dos principais momentos da escola ocorria por ocasião dos exames finais. A solenidade realizada todos os anos reunia os principais representantes da intelectualidade municipal para avaliar o aprendizado dos alunos. A questão avaliação na referida escola seguia a rigor a proposta apresentada nos regulamentos da instrução pública de Sergipe. Uma das principais características de tais avaliações era o rigor, que fazia com que a maior parte do alunado deixasse de ser promovido. Após as exigidas avaliações dos alunos a professora Izabel Esteves de Freitas redigia o termo de promoção:

Aos seis dias do mês de julho do ano de mil novecentos e trinta e dois, nesta cidade de Itabaiana, município do mesmo nome deste Estado, perante a professora da proferencia de costume Izabel Esteves de Freitas procedeu os exames de promoções conforme determina o artigo 69 do Regulamento da Instrução Pública (FREITAS, 1932, p. 27).

Ao enunciar os exames de promoção uma das primeiras atitudes foi declarar que os exames estavam em conformidade com o regulamento da instrução pública. $\mathrm{O}$ rigor e a idoneidade das avaliações eram legitimados tanto pelo fato está respaldado pelo regulamento, como pela presença de autoridades intelectuais, como professores e padres.

No entanto, as atas dos exames de promoções evidenciam também a face oculta das avaliações. A professora responsável pela cadeira ao expor a lista de aprovados e reprovados apresentava distinções entre os dois grupos. Enquanto o primeiro era agraciado com a publicação por extenso dos nomes de todos os alunos aprovados, acrescidos da respectiva pontuação obtida nas avaliações, os reprovados eram silenciados na memória, pois a professora expunha apenas uma lista com o número total de alunos reprovados. Deste modo, enquanto uns eram agraciados com todas as honras e pompas pela aprovação "para outro ano", os reprovados eram confinados a apenas números sem face, sem nomes. 
Pelo que consta na pequena bibliografia que registra a ação da professora Izabel Esteves de Freitas, a distinção dos alunos tidos como proficientes não ficava restrita ao momento dos exames finais. Ela também ocorria no decorrer das aulas, ou seja, o cotidiano escolar era impregnado pela s distinções dos melhores alunos. Vejamos como a professora se portava diante da aluna Maria Thetis Nunes:

$\mathrm{Na}$ sala da professora Izabel, Thetis desincumbia-se das tarefas com surpreendente desenvoltura. Permanecer muito tempo sentada e em silêncio jamais combinou com seu temperamento. A professora Isabelou Dona Bebé, como carinhosamente era tratada — sabia muito bem, tanto que pôs em ação o método de designa-la para tomar lições dos alunos do primeiro ano.

Com uma cajadada não matou dois coelhos, e sim três. Indiretamente pôs a nu a vocação de sua aluna que, num futuro muito breve, tornar-seia a conceituada professora Maria Thetis Nunes (SANTOS, 1999, p. 8586).

Mesmo o depoimento acima citado está tratando da biografia de uma das alunas ilustres de Izabel Esteves de Freitas, ele é revelador do grau de distinção que havia nas escolas isoladas do referido período. A autora mesmo buscando enobrecer a intelectualidade precoce de sua biografada, ela desvenda nuances do campo educacional sergipano e dos critérios intrinsecamente associados aos exames finais e do cotidiano escolar. A seleção dos aprovados de uma seção para outra era rigorosa e a maior parte do alunado ficava pelo caminho, pois nem todos conseguiam acumular o capital cultural necessário à aprovação, como pode ser observado.

\section{QUDRO IV}

Quadro com o resultado dos exames finais da escola da professora Izabel Esteves de Freitas de Itabaiana em

\begin{tabular}{|c|c|c|c|c|}
\hline $\begin{array}{c}\text { Classe para o qual } \\
\text { foi promovido }\end{array}$ & $\begin{array}{c}\text { Número de alunos } \\
\text { promovidos }\end{array}$ & Notas & $\begin{array}{c}\text { Número de alunos que } \\
\text { deixaram de ser } \\
\text { promovidos }\end{array}$ & $\begin{array}{c}\text { Número de alunos que } \\
\text { não foram aprovados }\end{array}$ \\
\hline $\begin{array}{c}1^{\mathrm{a}} \text { classe para a } 2^{\mathrm{a}} \\
\left(1^{\mathrm{a}} \text { seção) }\right.\end{array}$ & 00 & - & 02 & - \\
\hline $\begin{array}{c}1^{\mathrm{a}} \text { classe para a } 2^{\mathrm{a}} \\
\left(2^{\mathrm{a}} \text { seção) }\right.\end{array}$ & 05 & $\begin{array}{c}6 ; 3 ; 3 ; 3 \\
\mathrm{e} 3\end{array}$ & 08 & - \\
\hline $\begin{array}{c}1^{\mathrm{a}} \text { classe para a } 2^{\mathrm{a}} \\
\left(3^{\mathrm{a}} \text { seção) }\right.\end{array}$ & 01 & 6 & 02 & 04 \\
\hline $1^{\mathrm{a}}$ para a 2 $2^{\mathrm{a}}$ classe & 02 & 3 e 3 & - & 04 \\
\hline $2^{\mathrm{a}}$ para a $3^{\mathrm{a}}$ & 04 & $\begin{array}{c}6 ; 4,8 ; \\
4,8 \text { e } 4,7\end{array}$ & - & 01 \\
\hline $3^{\mathrm{a}}$ & 01 & 6 & - & - \\
\hline
\end{tabular}

Fonte: FREITAS, Izabel Esteves de. Livro de atas de exames finais da escola número um de Itabaiana.

Como se pode perceber, o número de alunos que não conseguiam a almejada promoção era bastante relevante, demonstrando o rigor adotado nas avaliações. Os quadros demonstrativos produzidos pela professora Izabel Esteves de Freitas ao final dos exames também consistia em um mecanismo de distinguir os alunos, apresentando as notas dos que conseguiram ser promovidos ao mesmo tempo em que ocultava as dos reprovados. Somando-se o número de alunos reprovados e os não promovidos ${ }^{2}$ temos um total de 17 , enquanto apenas 13 conseguiram passar pelos rigorosos exames. Isso demonstra que no 
espetáculo republicano das avaliações, o rigor era apresentado como sinônimo de qualidade, eficiência e racionalidade. Eram os valores atribuídos à república emergindo no cenário do ensino primário sergipano.

Devemos lembrar que cada modelo institucional detenha um valor simbólico, uma funcionalidade determinada na conjuntura dos primeiros decênios republicanos. Os valores do novo regime deveriam aflora de acordo com a localização e a finalidade. Nos grandes centros das grandes cidades eclodiam os imponentes grupos escolares, verdadeiros palácios da instrução pública, edifícios racionalizados, modernos e foco da propaganda da civilização emergente. Nas demais localidades sobressaiam as modestas escolas isoladas, que apesar de não serem badaladas e fruto dos discursos republicanos, que as associavam ao Império, se tornaram importantes focos de visibilidade por meio de seus exames finais.

Se não existiam prédios majestosos para serem vistosos pela população, as escolas isoladas exibiam o seu rigor. Com isso, a redução do número de analfabetos e o conseqüente aumento de eleitores, fortalecendo a insipiente democracia, foram configurados nas escolas isoladas. Não podemos dizer que esse processo se deu em pleno silêncio, pois em algumas localidades essas escolas conseguiram visibilidade, tornando-se alvo das visitações de lideranças políticas, religiosas e intelectuais.

\section{Considerações Finais: Um novo olhar sobre as Escolas Isoladas}

A escola isolada número um de Itabaiana pode ser vista como um relevante objeto de estudo. Várias são as temáticas que podem ser focadas pelo olhar do historiador, como prática docente, cotidiano escolar, biografia das professoras e avaliação. A documentação concernente às escolas isoladas está no Arquivo Público Estadual de Sergipe, na qual podemos destacar os termos de visita da inspetoria, as mensagens e relatórios de presidente do estado, livros de freqüência e os termos de exames finais. Neste sentido, podemos dizer que existe uma considerável gama documental a respeito das escolas isoladas.

Mesmo a historiografia tratando as escolas isoladas como legítimas representantes do atraso, herança da falta de definição de política pública para o setor educacional durante o período imperial, elas desempenharam a importante função de promover a redução do número de analfabetos e a difusão do conhecimento por regiões inóspitas na referida época, na qual dificilmente as crianças teriam oportunidade de deslocar-se para as escolas das cidades e vilas vizinhas.

Ao lançar um olhar aligeirado sobre o período republicano a monumentalidade arquitetônica dos grupos escolares prende a atenção de todos, num primeiro momento. Todavia, se olharmos mais atentamente para o universo educacional sergipano deste período, podemos constatar que eram as escolas isoladas que cumpriam a um dos principais anseios do regime recém-implantado: reduzir o analfabetismo para ampliar e fortalecer a democracia.

No caso de Itabaiana a relevância das escolas isoladas é ainda maior. O município passou muito tempo desprovido de grupos escolares, que só foi implantado em 1937. Deste modo, a educação itabaianense durante as três primeiras décadas do Século XX foi realizado de forma exclusiva pelas escolas isoladas ou por escolas particulares, também escassas na cidade.

As avaliações e os exames finais constituíam um momento importante para a escola, pois reunia algumas das principais autoridades para avaliarem o desempenho dos alunos, que na maioria das vezes eram reprovados. No entanto para aqueles que conseguiam a proeza da aprovação as mais diferentes distinções eram-lhes atribuídas. Com isso, podemos dizer que a escola isolada nos mostra duas novas facetas do ensino primário 
sergipano: as ações do campo educacional (por meio dos exames finais) e a sua relevância positiva para a redução do analfabetismo.

\section{Referências}

BOURDIEU, Pierre. "O Mercado de Bens Simbólicos”. In: A Economia das Trocas Simbólicas. $6^{a}$ ed. São Paulo: Perspectiva, 2005. p. 99- 181.

BOURDIEU, Pierre. Os usos sociais da ciência: por uma sociologia clínica do campo científico. Trad. Denice Bárbara Catani. São Paulo: UNESP, 2004

BOURDIEU, Pierre. "Gênese e Estrutura do Campo Religioso". In: A Economia das Trocas Simbólicas. $6^{a}$ ed.. Trad. Sergio Miceli. São Paulo: Perspectiva, 2005. p. 27-98.

BOURDIEU, Pierre. Itinerário. In: Coisas Ditas. Trad. Cássia R. da Silveira e Denise Moreno Pegorim. São Paulo: Brasiliense, 1990. p. 09-73

BOURDIEU, Pierre; PASSERON, Jean Claude. A Reprodução: elementos para uma teoria do sistema de ensino. $2^{\mathrm{a}}$ ed. Trad. Reynaldo Bairão.Rio de Janeiro: Livraria Francisco Alves, 1982.

CARVALHO, Vlademir Souza. Santas Almas de Itabaiana Grande. Itabaiana: Edições O Serrano, 1973

CATANI, A. M.; CATANI, B. C.; PEREIRA, G. R. de. "As apropriações da obra de Pierre Bourdieu no campo educacional brasileiro através de periódicos da área". Revista Brasileira de Educação. Mai-ago, $n^{\circ}$ 017. São Paulo: Associação Nacional de Pós Graduação e Pesquisa em Educação. p. 63-85.

CHAMPAGNE, Patrick. "Prefácio". In: BOURDIEU, Pierre. Os usos sociais da ciência: por uma sociologia clínica do campo científico. São Paulo: UNESP, 2004. p. 7-15.

CHARLE, Christophe; ROCHE, Daniel. Pierre Bourdieu e a História. In: Le Monde. Trad. Flávio M. Heinz, 2003 (não publicado).

SANTOS, Maria Nely. Professora Thetis: uma vida. Aracaju: Gráfica Pontual, 1999.

SAVIANI, Dermeval. Escola e Democracia. Polêmicas do nosso tempo. $27^{\mathrm{a}}$ ed. Campinas-SP: Autores Associados, 1993.

SEBRÃO SOBRINHO, José. Tobias Barreto, o desconhecido (gênio e desgraça). Vol. I. Aracaju: Imprensa Oficial, 1941.

Notas

\footnotetext{
${ }^{1}$ Doutorando em História na Universidade Federal Fluminense, sob a orientação da professora Doutora Martha Campos Abreu. Bolsista CAPES. Professor da Faculdade Pio Décimo e membro da diretoria do Instituto Histórico e Geográfico de Sergipe. Email: magnohistoria@gmail.com

${ }^{2}$ Havia distinção entre os alunos reprovados e os não promovidos. Estes são referentes aos alunos da primeira classe, que era dividida em seções de acordo com o estágio de aprendizado e não havia reprovação, apenas a promoção para a seção seguinte. Já os primeiros são referentes às classes subseqüentes e poderia ocorrer reprovações.

Recebido em novembro-12

Aprovado em setembro-13
} 